\title{
Crowdfunding e desempenho eleitoral no Brasil: análise estatística das eleições para deputado federal em 2018
}

Leonardo Secchi 1

Marcos Vinicio Wink Junior 1

Cryslan Jorjan de Moraes ${ }^{2}$

1 Universidade do Estado de Santa Catarina / Centro de Ciências da Administração e Sócio-Econômicas, Programa de

Pós-Graduação em Administração, Florianópolis / SC - Brasil

2 Câmara Municipal de São José, São José / SC - Brasil

\begin{abstract}
O artigo busca analisar o desempenho do financiamento coletivo (crowdfunding) como estratégia de arrecadação de recursos para a campanha eleitoral a deputado federal nas eleições de 2018. Também foi analisada a influência de características socioeconômicas e demográficas dos candidatos associada à decisão de adoção do financiamento coletivo como alternativa arrecadatória na campanha eleitoral. A metodologia utilizada foi a de regressão logística, considerando as seguintes variáveis independentes: valores arrecadados, escolaridade, idade, raça e estado civil do candidato, além de ideologia, tamanho e antiguidade do partido. As variáveis dependentes binárias foram: utilização ou não do crowdfunding e sucesso ou insucesso eleitoral. A fonte de dados foi o repositório de dados eleitorais do Tribunal Superior Eleitoral (TSE), com informações de todos os candidatos a deputado federal, de todos os estados brasileiros, no pleito de 2018. Entre os resultados obtidos, encontra-se que o crowdfunding foi estatisticamente mais usado por candidatos brancos, jovens, de alta escolaridade e da região Sul. Há evidências também de que o crowdfunding seja uma estratégia eleitoral utilizada sobretudo por candidatos de partidos de criação recente, de esquerda, centro-esquerda ou de direita - os de centro e centro-direita tiveram menor utilização -, e daqueles com maior bancada. Por fim, o modelo econométrico aponta um acréscimo médio de 5,55 pontos percentuais na probabilidade de sucesso eleitoral dos candidatos que se valeram do crowdfunding.
\end{abstract}

Palavras-chave: eleições legislativas; financiamento eleitoral; financiamento coletivo; crowdfunding; Brasil.

\section{Crowdfunding y desempeño electoral en Brasil: análisis estadístico de las elecciones a diputado federal en 2018}

El artículo busca analizar el desempeño del crowdfunding como estrategia de captación de fondos para la campaña electoral de diputado federal en las elecciones generales de Brasil en 2018. También se analizó la influencia de las características socioeconómicas y demográficas de los candidatos asociada a la decisión de adoptar el financiamiento colectivo como alternativa de recaudación en la campaña electoral. Se utilizó la metodología de regresión logística considerando las siguientes variables independientes: valores recaudados, nivel de instrucción, edad, raza y estado civil del candidato, además de la ideología, tamaño y antigüedad de su partido político. Las variables dependientes binarias fueron: uso o no de crowdfunding y éxito o fracaso electoral. La fuente de datos fue el Tribunal Superior Electoral de Brasil (TSE), con información de todos los candidatos a diputado federal en la elección de 2018. Entre los resultados alcanzados está que el crowdfunding fue estadísticamente más utilizado por candidatos blancos, jóvenes y de alto nivel de escolaridad y de la región sur de Brasil. También hay evidencia de que el crowdfunding es una estrategia electoral utilizada especialmente por candidatos de partidos de reciente creación, de izquierda, centro-izquierda o derecha (los de centro y centro-derecha registraron menos uso) y tamaño de los partidos políticos. Finalmente, el modelo econométrico apunta a un aumento promedio del 5,55 puntos porcentuales en la probabilidad de éxito electoral de los candidatos que utilizaron el crowdfunding.

Palabras clave: elecciones legislativas; financiación electoral; recaudación de fondos; crowdfunding; Brasil. 


\section{Crowdfunding and electoral performance in Brazil: statistical analysis of the elections for federal deputy in 2018}

The article seeks to analyze the performance of crowdfunding as a fundraising strategy in the election campaign for the Brazilian Congress in the 2018 general elections. The article also analyzes the influence of the socioeconomic and demographic profiles of the candidates associated with the decision to adopt crowdfunding. The methodology used was logistic regression, considering the following independent variables: funds raised, education, age, race, and marital status of the candidate, in addition to the party's ideology, size, and age of the party. The binary dependent variables were: use of crowdfunding (or not) and the campaign's outcome. The data source was the Electoral Data Repository of the Brazilian Superior Electoral Court (TSE), with information from all candidates running for federal deputy in all Brazilian states in the 2018 general elections. The resulting analysis shows that crowdfunding was statistically more used by white, young, highly educated candidates from the Southern region of Brazil. There is also evidence that crowdfunding is an electoral strategy used especially by candidates from recently created parties, from the left, center-left or right (those in the center and center-right did not use crowdfunding as frequently) and larger parties. Finally, the econometric model points to an average increase of 5.55 percentage points in the probability of electoral success of candidates using crowdfunding.

Keywords: legislative elections; electoral funding; electoral campaigning; crowdfunding; Brazil.

\section{AGRADECIMENTOS}

O autor Marcos Vinicio Wink Junior agradece à Fundação de Amparo à Pesquisa e Inovação do Estado de Santa Catarina (FAPESC) pelo apoio financeiro.

\section{INTRODUÇÃO}

Crowdfunding pode ser definido como a atividade de mobilização de pessoas para arrecadação de fundos a serem usados em algum projeto (Kusuramani \& Zo, 2019). Dessa forma, ele vem sendo utilizado como estratégia de arrecadação de recursos para projetos e causas sociais e políticas, criação de novas tecnologias e lançamento de ideias, produtos, serviços e organizações (Amedomar, 2015; Monteiro, 2014).

O crowdfunding eleitoral é entendido como o processo de doação financeira em que muitos indivíduos doam pequenas somas de dinheiro para apoiar uma campanha eleitoral (Idea, 2018; Sokolov, 2015). Em diversos países, essa estratégia vem se destacando como uma alternativa arrecadatória de fundos para eleições, em especial com a recente proliferação de plataformas on-line dedicadas a esse serviço.

Os potenciais benefícios do financiamento coletivo de campanha são aumento da transparência, diminuição da corrupção eleitoral, combate à captura dos partidos e dos políticos por grupos econômicos ou grandes doadores, fomento aos valores democráticos, promoção da igualdade de competição eleitoral e aumento do senso de cidadania ativa (Idea, 2018; Mohallem \& Costa, 2015; Santano, 2016). Também é tema de pesquisa a própria motivação ao crowdfunding eleitoral pelos doadores, sendo as principais conclusões congruência entre a visão de mundo do doador e a do candidato ou do partido, confiança, recompensa, reconhecimento, senso de pertencimento, qualidade das ideias/propostas, entre outros (Kusuramani \& Zo, 2019).

Outro importante efeito que tem sido estudado em diversos países é a relação entre o engajamento coletivo na campanha e sua influência no desempenho eleitoral do candidato, da lista ou do partido 
que se vale do crowdfunding como estratégia de arrecadação de recursos financeiros (Bonneau, 2007; Hindman, 2005; Sebold, Limbocker, Dowdle \& Stewart 2012).

No Brasil, o crowdfunding eleitoral surgiu nas eleições municipais de 2016, quando alguns poucos candidatos montaram suas plataformas próprias de arrecadação financeira nessa modalidade. O maior destaque foi o candidato à prefeitura do Rio de Janeiro Marcelo Freixo (Psol), que construiu uma plataforma própria em seu website e conseguiu arrecadar, durante primeiro e segundo turnos, um total de $\mathrm{R}$ \$ 1,8 milhão doados por 14.022 doadores, com um tíquete médio de doação de $\mathrm{R} \$ 129,86$ (Bando, 2020). No entanto, a disseminação do crowdfunding entre as candidaturas foi restrita, pois a legislação eleitoral ainda não permitia intermediários entre o doador e o candidato/partido, obrigando cada campanha a construir a própria plataforma eletrônica de arrecadação eleitoral.

Em 2017, a Lei $\mathrm{n}^{\circ} 13.488$ regulamentou o crowdfunding eleitoral, permitindo que entidades arrecadadoras pudessem atuar como prestadoras de serviço de recebimento de fundos para as campanhas dos candidatos. Essa lei teve instrução eleitoral com a Resolução no $23.553 / 2017$, do Tribunal Superior Eleitoral (TSE), em que empresas foram autorizadas a solicitar registro para oferecer serviço de crowdfunding, ou "vaquinhas" virtuais, desde que seguissem uma série de requisitos. As eleições gerais brasileiras de 2018 foram, portanto, as primeiras a utilizar de forma difusa e maciça essa modalidade de financiamento, permitindo que empresas arrecadadoras - plataformas de crowdfunding - intermediassem o processo de doação entre eleitores e candidatos.

Este estudo tem como objetivo analisar a relação entre a estratégia de arrecadação de recursos para campanha por meio do crowdfunding e as chances de sucesso nas eleições para deputado federal em 2018. Além disso, investigam-se possíveis características socioeconômicas e demográficas associadas aos candidatos que decidiram adotar o financiamento coletivo como alternativa arrecadatória na campanha eleitoral.

Para tanto, a principal estratégia empírica considerada foi o método de regressão logística visando à estimação de probabilidades de utilização do crowdfunding e de sucesso eleitoral. Estimações alternativas, que consideram o financiamento coletivo uma variável quantitativa (valor arrecadado), também foram realizadas para verificar a robustez dos resultados. A fonte dos dados foi o repositório de dados eleitorais do TSE, com delimitação restrita ao processo eleitoral para deputado federal nas eleições de 2018, a primeira a ter o financiamento coletivo de campanha regulamentado pela legislação, mediado por plataformas on-line de coleta de recursos dessa modalidade, e, até o momento, a única com informação completa sobre prestação de contas eleitorais associadas a crowdfuding. Esse recorte também se justifica por se tratar da primeira eleição geral brasileira em que doações empresariais estavam proibidas, o que motivou muitos candidatos a buscar outras fontes de recursos além dos fundos partidários e eleitorais.

\section{FINANCIAMENTO DE CAMPANHAS ELEITORAIS NO BRASIL}

Segundo Speck, por financiamento de campanhas eleitorais se entendem "os recursos materiais empregados pelos competidores em eleições populares para organizar a campanha e convencer os cidadãos a lhes conferirem o voto" (Speck, 2007, p. 154). O financiamento eleitoral pode ser oriundo de custeio público, privado ou misto. Além disso, é classificado como direto ou indireto, quando se trata de subsídio financeiro (direto) ou por meio da concessão de vantagens ou de serviços (indiretos), tendo, no último caso, a necessidade de quantificar os custos em dinheiro e contabilizá-lo como receita. 
Sacchet e Speck (2012) apontam que os recursos financeiros são cruciais ao sucesso de uma eleição no Brasil. Em análises da relação entre os recursos arrecadados para a campanha e o desempenho eleitoral no Brasil, é possível perceber que as variáveis estão fortemente associadas, pressionando as candidaturas a buscarem dinheiro como elemento fundamental à vitória na competição eleitoral (Cervi, 2013; Mancuso \& Speck, 2015).

Sallaberry e Flach (2019) aplicaram um modelo de regressão logística para identificar a correlação entre quantidade total de recursos arrecadados nas eleições gerais de 2014 e 2018 no Brasil e o respectivo desempenho eleitoral das candidaturas. Os autores notaram que o poderio econômico - quantidade de recursos eleitorais arrecadados - é o fator que mais influencia as chances de sucesso eleitoral, quando comparado com outras variáveis, como idade, sexo, estado civil e situação de reeleição.

Esse processo, contudo, é evidenciado por fartas imperfeições, em especial no que diz respeito aos valores básicos de democracia e justiça. Speck (2007) encontrou na dinâmica do financiamento eleitoral uma das causas da corrupção, ao ilustrar os modos de arrecadação ilegal de recursos de campanha e analisar conceitualmente os paralelismos e as diferenças entre a corrupção com fins privados e políticos. Para o autor, uma melhor regulação do financiamento político pode estabelecer um retorno positivo no combate à corrupção, no sentido de trazer mais transparência em todo o processo eleitoral.

Por outro lado, estudos sobre a motivação para a doação eleitoral em geral, e ao crowdfunding em específico, têm apontado para um maior engajamento dos doadores, senso de pertencimento e efeitos positivos sobre a confiança e a percepção da qualidade das propostas do candidato (Kusuramani \& Zo, 2019). Ou seja, a decisão de um candidato em fazer ou não crowdfunding pode impactar nos níveis de motivação e engajamento de seus doadores.

Desde 1997, quando foi aprovado a chamada Lei das Eleições (Lei 9.504/97), o financiamento de campanhas de partidos políticos e seus candidatos elencava diversas formas de arrecadação de recursos financeiros, entre elas doações de pessoas físicas e jurídicas, além de recursos dos partidos oriundos do fundo partidário e dos próprios candidatos.

As doações provenientes de pessoas jurídicas (empresas) dominaram o financiamento das campanhas eleitorais até 2014, trazendo uma série de deturpações e riscos à democracia, como o desequilíbrio de forças eleitorais, investimento pragmático em partidos e candidatos que pudessem retribuir para a doações, corrupção e captura eleitoral (Mancuso, Horochovski \& Camargo, 2016; McMenamin, 2012; Santos, 2009; Zovatto, 2005). Por outro lado, não há como sustentar que a substituição das doações empresariais por financiamento público seria capaz de exitinguir atos eleitorais corruptos. Como indicado por Rubio, "o efeito do financiamento público como antídoto contra a corrupção não tem corroboração empírica suficiente" (Rubio, 2005, p. 10).

A partir de 2015, doações empresariais foram proibidas pelo Supremo Tribunal Federal (STF), que julgou essa fonte como inconstitucional, por violar a normalidade e a legitimidade das eleições. Tal decisão trouxe uma série de desafios ao processo eleitoral, em especial para o das eleições municipais de 2016.

Em 2017, para fins de compensação da perda de importante fonte de recursos eleitorais, o Congresso Nacional aprovou a Lei no 13.488/2017, que instituiu o Fundo Especial de Financiamento de Campanha (FEFC) e regulamentou o crowdfunding eleitoral, permitindo, assim, que candidatos pudessem contar com novas fontes de recursos públicos e privados, com base em financiamento coletivo eleitoral, em plataformas virtuais. Sem o dinheiro das empresas, o FEFC, também conhecido como Fundão Eleitoral, se tornou a origem predominante de recursos para campanhas eleitorais. $\mathrm{O}$ fundo é dividido entre os 
partidos segundo sua representação no Congresso Nacional, que o distribuem internamente, conforme critérios próprios. Para as eleições de 2018, o valor distribuído foi de $\mathrm{R} \$ 1,7$ bilhão.

Pelo lado da doação individual, a Lei no 9.504/1997 já autorizava a contribuição de pessoas físicas para as campanhas eleitorais, obedecendo ao limite estabelecido de 10\% (dez por cento) dos rendimentos brutos auferidos pelo doador no ano anterior à eleição. Com a proibição das doações empresariais para campanhas a partir de 2015, e somado ao crescente aumento de doações de pessoas físicas, partidos e coligações buscavam novas formas de arrecadação.

Com a aprovação da Lei no $13.488 / 2017$, ficou instituído que entidades privadas promovessem serviços de financiamento coletivo por meio digital, aplicativos eletrônicos e outros recursos similares. Com o sistema de arrecadação realizado de maneira totalmente on-line para a modalidade, a legislação indicou que as empresas mediadoras deveriam ser cadastradas e que os doadores tivessem identificação individual obrigatória. Com as eleições gerais de 2018, o crowdfunding eleitoral se tornou realidade no Brasil.

Com essas mudanças nas regras do processo eleitoral, o modelo de financiamento de campanhas no Brasil é misto (público e privado), com origem dos recursos restrita a cinco possibilidades: do próprio candidato, do partido político, do FEFC, oriundos de doação de indivíduos - na qual está contida o crowdfunding eleitoral - e oriundos de outros candidatos naquele pleito eleitoral - por exemplo, um candidato a deputado federal pode doar para um candidato a deputado estadual. Há tetos máximos de arrecadação de recursos fixados para cada candidatura, de acordo com o cargo pleiteado. Nas eleições para deputado federal em 2018, por exemplo, o teto máximo de arrecadação por candidato foi de R \$ 2,5 milhões. No caso do crowdfunding, a Resolução n² 23.553/2017 do TSE estabeleceu teto de $\mathrm{R} \$ 1.064,10$, por pessoa, diariamente. Todas as receitas e as despesas de campanha eleitoral devem ser registradas e declaradas à autoridade judicial eleitoral, os Tribunais Regionais Eleitorais (TREs), sob pena de incorrer em crime eleitoral.

Para fins de definição operativa deste estudo sobre o crowdfunding eleitoral nas eleições para deputado federal em 2018, portanto, realizou-se a seguinte delimitação: recursos financeiros doados por indivíduos a candidatos, por meio de plataformas virtuais credenciadas pelo TSE, em todos os estados, durante a pré-campanha e a campanha eleitoral. Com isso, não fazem parte do objeto de estudo as doações econômicas (não financeiras), as feitas a partidos políticos, aquelas em valores maiores que as doações diárias permitidas nas plataformas virtuais ou as realizadas na conta corrente dos candidatos. A seguir, apresentam-se as demais delimitações metodológicas e a aplicação de ferramentas estatísticas para a verificação da relação das variáveis crowdfunding eleitoral e desempenho eleitoral no Brasil, sobretudo para deputado federal, no pleito de 2018.

\section{METODOLOGIA E DADOS}

A metodologia empregada buscou analisar a relação entre a estratégia de arrecadação de recursos para campanha por meio do crowdfunding e as chances de sucesso nas eleições para deputado federal em 2018. Além disso, investigaram-se possíveis características socioeconômicas e demográficas associadas à decisão do candidato de utilizar o financiamento coletivo como alternativa arrecadatória na campanha eleitoral.

A fonte utilizada no presente estudo foi o repositório de dados eleitorais do TSE de todos os candidatos a deputado federal, em todos os estados, no ano de 2018. Originalmente, a base de dados tinha 8.588 observações. Considerando apenas os candidatos que tiveram todas as informações de interesse divulgadas, a amostra totalizou 7.484 observações. 
Como estratégia empírica principal, esta pesquisa empregou a metodologia de regressão logística pelo software Stata. Essa forma de estimativa é indicada em casos cuja variável dependente é binária (dummy), por permitir o cálculo direto de probabilidades de determinado evento em função de variáveis independentes. A metodologia de regressão logística também é bastante consolidada na literatura empírica sobre previsão de sucesso eleitoral (Dias, Nossa \& Monte-Mor, 2018; Dufloth, Horta, M. M. Silva, Costa \& Rocha, 2019; Sallberry \& Flach, 2019).

No presente estudo, as variáveis dependentes binárias consideradas indicaram se o candidato usou o crowdfunding como alternativa de financiamento de campanha e se foi eleito ao cargo de deputado federal em 2018. Dessa forma, a primeira regressão tem variável dependente, que assumiu valor 1, caso o candidato tenha utilizado o financiamento coletivo, e 0 , caso contrário. Já na segunda especificação, a variável dependente assumiu valor 1 , se o candidato foi eleito, e 0 , se não foi eleito. No caso da segunda regressão, a variável dummy de utilização de crowdfunding foi usada como a variável explicativa de interesse. Como checagem de robustez dos resultados, foram testadas também especificações alternativas, que consideram o crowdfunding uma variável quantitativa (valor arrecadado). As demais variáveis independentes, presentes em ambas as regressões, estão no Quadro 1.

\section{QUADRO 1 VARIÁVEIS EXPLICATIVAS}

$\begin{array}{ll}\begin{array}{l}\text { Variável explicativa } \\ \text { Crowdfunding }\end{array} & \begin{array}{l}\text { Descrição } \\ \text { Dummy que indica se o candidato usou financiamento coletivo. } \\ \text { Partido com menos de } 5 \text { anos }\end{array} \\ \text { Ideologia partidária } & \begin{array}{l}\text { Dummies que indicam se o partido é de esquerda, centro-esquerda, centro, } \\ \text { centro-direita ou direita. }\end{array} \\ \text { Partidos na coligação } & \text { Número de legendas coligadas ao partido do candidato. } \\ \text { Tamanho do partido } & \text { Número de candidatos eleitos pelo partido para deputado federal em } 2014 . \\ \text { Candidato à reeleição } & \text { Dummy que indica se é candidato à reeleição. } \\ \text { Receita de campanha } \\ \text { (em R\$ 1.000.000,00) }\end{array}$

Fonte: Elaborado pelos autores. 
Entre as variáveis explicativas, merece detalhamento a categorização ideológica dos partidos. Com esse objetivo, foi realizada classificação própria, com base em Tarouco e Madeira (2015), que categorizaram os partidos com base num survey com cientistas políticos filiados à Associação Brasileira de Ciência Política (ABCP). A escala adotada classificou os partidos existentes em 2010 numa escala de 1 (máximo à esquerda) a 7 (máximo à direita). Baseado nessa escala de Tarouco e Madeira (2015), o presente estudo estabeleceu as linhas de corte entre as cinco categorias de interesse: esquerda ( 1 a 2,2), centro-esquerda ( 2,3 a 3,9), centro (4 a 5), centro-direita $(5,1$ a 5,9), direita (6 a 7). Essas linhas de corte foram estabelecidas de maneira arbitrária, na tentativa de manter uma distribuição intuitiva e mais próxima da normal, com menor número partidos nos extremos e maior quantidade nas posições próximas ao centro. O detalhamento de tal classificação pode ser encontrado no Apêndice.

Para os partidos que não foram classificados na escala de Tarouco e Madeira (2015), e nos casos daqueles que foram recentemente criados, fundidos ou incorporados, foi feita categorização autônoma com base nos estudos de Scheeffer (2018), Zucco e Powell (2021), bem como na leitura de estatutos e manifestos partidários, chegando-se à seguinte distribuição das siglas:

- Esquerda: PCO, PSTU, Psol, PCB e UP.

- Centro-esquerda: PCdoB (já incorporado o PPL), PT, PSB, PDT, PROS e PV.

- Centro: Avante, PSDB, MDB, Cidadania, Rede, PMN, PTB, SD e PMB.

- Centro-direita: PTC, Podemos (já incorporado o PHS), Republicanos, PSC, PRTB, DC, PL, Patriota (já incorporado o PRP) e PSD.

- Direita: PP, DEM, PSL e Novo.

As equações utilizadas para estimar as probabilidades das variáveis dependentes neste estudo são:

$$
\begin{gathered}
\text { Crowdfunding }_{i}=\alpha_{1}+\beta X_{i}+\theta_{i}+\varepsilon_{1 i} \\
\text { Elected }_{i}=\alpha_{1}+\alpha_{2} \text { Crowdfunding }_{i}+\beta X_{i}+\theta_{i}+\varepsilon_{2 i}
\end{gathered}
$$

Na fórmula acima, Crowdfunding $e_{i}$ é uma variável dummy que assume valor 1 caso o candidato a deputado federal $i$ tenha usado a estratégia de financiamento coletivo na campanha eleitoral de 2018; $X_{i}$ representa o vetor de características observáveis do candidato $i$, apresentadas no Quadro 1; $\theta i$ é o efeito fixo de unidade da federação (UF); e $\varepsilon_{1 i}$ é o termo de erro aleatório. Já com relação à segunda equação, a variável dummy Eleito ${ }_{i}$ assume valor 1 se o candidato a deputado federal $i$ foi eleito em 2018, enquanto $\varepsilon_{2 i}$ representa o termo de erro da segunda estimação. Ambas as especificações foram modeladas por regressão logística que se vale da máxima verossimilhança como método de estimação. 


\section{RESULTADOS}

Esta seção apresenta os resultados empíricos da pesquisa. Em primeiro lugar, é feita uma análise descritiva dos dados. Na sequência, são apresentados e discutidos os resultados das regressões logísticas estimadas.

\subsection{Estatísticas Descritivas}

A Tabela 1 apresenta as estatísticas descritivas da amostra de candidatos a deputado federal nas eleições de 2018. Para facilitar o entendimento, a amostra foi dividida entre os que utilizaram e os que não utilizaram a estratégia de crowdfunding para arrecadação de recursos de campanha. A análise descritiva proposta aqui não busca testar significâncias estatísticas; apenas encontrar diferenças pontuais de médias e proporções (caso das variáveis binárias). Análises estatísticas mais aprofundadas serão realizadas na subseção seguinte.

Primeiramente, verifica-se que só $11 \%$ (813/7.484) dos candidatos presentes na amostra utilizaram o financiamento coletivo. Nesse grupo, essa modalidade arrecadatória gerou, em média, cerca de R\$ 6 mil para a campanha de cada postulante.

Com relação às filiações dos candidatos que usaram o crowdfunding, percebe-se, comparado com os que não recorreram ao financiamento coletivo, maior proporção de partidos com menos de 5 anos (25\% contra $5 \%$ ), de esquerda ( $11 \%$ contra $8 \%$ ), centro-esquerda ( $29 \%$ contra $22 \%$ ) e direita ( $29 \%$ contra $11 \%$ ). Candidatos de partidos maiores, com maior representatividade na Câmara Federal e com menos legendas na coligação também têm maior probabilidade de utilizar a estratégia de financiamento coletivo de campanha. Enquanto a bancada média dos partidos daqueles candidatos que utilizaram crowdfunding era de 19,86 Deputados Federais por partido, para os candidatos que não utilizaram crowdfunding o tamanho médio da bancada de seus partidos na Câmara Federal era de 16,27. Da mesma forma, esses candidatos que utilizaram crowdfunding pertenciam a coligações eleitorais com, em média, 1,79 partido na coligação, enquanto aqueles candidatos que não utilizaram o crowdfunding pertenciam a coligações com número médio de 1,87 partidos na coligação. Por fim, candidatos à reeleição têm maior chance de utilizarem o financiamento coletivo ( $12 \%$ contra $5 \%$ ).

A arrecadação total de campanha dos candidatos a deputado federal em 2018 presentes na amostra foi de cerca de $\mathrm{R} \$ 1,3$ bilhão, enquanto por crowdfunding foi de aproximadamente $\mathrm{R} \$ 5,2$ milhões. Em média, as receitas por financiamento coletivo representaram $10 \%$ da arrecadação total de cada candidato que utilizou essa estratégia. Embora a arrecadação por essa modalidade ainda não seja significativa, em comparação com as demais fontes, ela é, em média, mais comum para aqueles com maior receita total de campanha (R $\$ 331$ mil contra R 164 mil).

O perfil social do candidato que utilizou o crowdfunding nas eleições para deputado federal em 2018 também pode ser analisado na Tabela 2. As estatísticas descritivas indicam que aqueles que optaram por essa estratégia são, em média, mais escolarizados (14,47 anos de educação contra 12,95) e jovens (47,39 contra 48,34), quando comparados com os que não recorreram ao financiamento coletivo. Em termos proporcionais, são também de raça branca ( $73 \%$ contra $58 \%$ ) e casados ( $58 \%$ contra $55 \%$ ). 


\section{TABELA 1 ESTATÍSTICAS DESCRITIVAS}

\begin{tabular}{|c|c|c|c|c|c|}
\hline & \multirow[b]{2}{*}{ Variável } & \multicolumn{2}{|c|}{ Com crowdfunding } & \multicolumn{2}{|c|}{ Sem crowdfunding } \\
\hline & & Média & Desvio-padrão & Média & Desvio-padrão \\
\hline \multirow{7}{*}{$\begin{array}{l}\text { Variáveis } \\
\text { binárias }\end{array}$} & Partido com menos de 5 anos & 0,25 & 0,43 & 0,05 & 0,22 \\
\hline & Partido de esquerda & 0,11 & 0,32 & 0,08 & 0,27 \\
\hline & Partido de centro-esquerda & 0,29 & 0,45 & 0,22 & 0,42 \\
\hline & Partido de centro & 0,19 & 0,39 & 0,24 & 0,43 \\
\hline & Partido de centro-direita & 0,12 & 0,32 & 0,36 & 0,48 \\
\hline & Partido de direita & 0,29 & 0,45 & 0,11 & 0,31 \\
\hline & Branco & 0,73 & 0,45 & 0,58 & 0,49 \\
\hline \multirow{11}{*}{$\begin{array}{c}\text { Variáveis } \\
\text { quantitativas }\end{array}$} & Casado & 0,58 & 0,49 & 0,55 & 0,50 \\
\hline & Candidato à reeleicao & 0,12 & 0,32 & 0,05 & 0,21 \\
\hline & Partidos na coligação & 1,79 & 2,21 & 1,87 & 2,10 \\
\hline & Tamanho do partido & 19,86 & 25,47 & 16,27 & 20,73 \\
\hline & $\begin{array}{l}\text { Receita de crowdfunding na campanha } \\
\text { (em } \mathrm{R} \$ 1.000 .000 .00)\end{array}$ & 0,006 & 0,014 & & \\
\hline & Receita total de campanha (em $\mathrm{R} \$$ & & & & \\
\hline & 1.000.000.00) & 0,331 & 0,523 & 0,164 & 0,418 \\
\hline & Receita crowdfunding/ Receita total & 0,10 & 0,15 & & \\
\hline & Anos de escolaridade & 14,47 & 1,53 & 12,95 & 2,76 \\
\hline & Idade & 47,39 & 11,74 & 48,34 & 11,40 \\
\hline & Observações & \multicolumn{2}{|c|}{813} & \multicolumn{2}{|c|}{6.671} \\
\hline
\end{tabular}

Fonte: Elaborada pelos autores.

\subsection{Determinantes da utilização do crowdfunding}

A análise descritiva dos dados permite aventar algumas hipóteses sobre o perfil do candidato que se valeu da estratégia de financiamento coletivo na eleição para deputado federal em 2018. Com base nessas relações preliminares, construiu-se um modelo de regressão logística, conforme equação (1), que estima as probabilidades associadas a cada determinante isoladamente. Os resultados dos efeitos marginais de cada determinante são apresentados na Tabela 2.

Segundo as estimações, apenas as variáveis que identificam se os candidatos concorrem por partidos de centro-direita, se buscam a reeleição e se são casados não afetam estatisticamente a probabilidade de usar o crowdfunding. Todas as demais variáveis analisadas são estatisticamente significativas, com pelo menos $10 \%$ de nível de significância.

Os resultados dos efeitos marginais médios da regressão logística apontam que candidatos que concorreram por partidos com menos de 5 anos de criação têm aumento de 31,81 pontos percentuais 
(p.p.) na probabilidade de utilizar crowdfunding. Com relação à orientação política, postulantes de partidos de esquerda, centro-esquerda e direita têm probabilidades superiores, 21,76, 10,78 e 12,53 pontos percentuais, respectivamente, em relação aos de centro. A variável dummy que identifica partidos de centro foi retirada do modelo por ser a categoria de referência. De forma semelhante, candidatos de partidos maiores, com mais legendas na coligação e maiores arrecadações totais de campanha, mais escolaridade, mais jovens e brancos tendem a ter, estatisticamente, maior probabilidade de utilizar o crowdfunding. Foi testada a mesma especificação com arrecadação de campanha descontando a receita por crowdfunding, não havendo mudanças de sinal ou de magnitude nas estimativas, o que sugere que uma possível endogeneidade da variável independente não altera as interpretações.

\section{TABELA 2 RESULTADO DA ESTIMAÇÃO PARA OS DETERMINANTES DA PROBABILIDADE DE UTILIZAÇÃO DO CROWDFUNDING}

\begin{tabular}{|c|c|c|c|}
\hline \multicolumn{4}{|c|}{ Efeito marginal (EP) - regressão logística } \\
\hline \multicolumn{4}{|c|}{ Variável dependente: $\operatorname{Pr}($ crowdfunding) } \\
\hline Partido com menos de 5 anos & $\begin{array}{c}0,3181^{\star \star \star} \\
(0,0255)\end{array}$ & Candidato à reeleição & $\begin{array}{c}0,0226 \\
(0,0182)\end{array}$ \\
\hline Partido de esquerda & $\begin{array}{c}0,2176^{\star \star \star} \\
(0,0280)\end{array}$ & $\begin{array}{c}\text { Receita de campanha (em } \mathrm{R} \$ \\
1.000 .000 .00)\end{array}$ & $\begin{array}{c}0,0401^{* * *} \\
(0,0087)\end{array}$ \\
\hline Partido de centro-esquerda & $\begin{array}{c}0,1078^{\star \star \star} \\
(0,0142)\end{array}$ & Anos de escolaridade & $\begin{array}{c}0,0231^{\star \star *} \\
(0,0027)\end{array}$ \\
\hline Partido de centro-direita & $\begin{array}{c}0,0102 \\
(0,0140)\end{array}$ & Idade & $\begin{array}{c}-0,0009^{\star * *} \\
(0,0003)\end{array}$ \\
\hline Partido de direita & $\begin{array}{c}0,1253^{\star \star \star} \\
(0,0169)\end{array}$ & Branco & $\begin{array}{l}0,0189 * * \\
(0,0075)\end{array}$ \\
\hline Partidos na coligação & $\begin{array}{l}0,0040^{\star \star} \\
(0,0020)\end{array}$ & Casado & $\begin{array}{l}0,0098 \\
(0,0067)\end{array}$ \\
\hline Tamanho do partido & $\begin{array}{c}0,0011^{\star \star \star} \\
(0,0002)\end{array}$ & & \\
\hline Efeito fixo de UF & & $\operatorname{Sim}$ & \\
\hline Pseudo-R2 & & 0,2058 & \\
\hline Observações & & 7.484 & \\
\hline
\end{tabular}

Notas: Efeitos marginais estimados e erros-padrão robustos entre parênteses.

Significância estatística: ${ }^{\star}$ significa valor- $\mathrm{P}<0,1$; ${ }^{* *}$ valor- $\mathrm{P}<0,05$; ${ }^{\star * *}$ valor- $\mathrm{P}<0,01$. Fonte: Elaborada pelos autores. 
Os resultados apresentados na Tabela 2 fornecem uma importante compreensão sobre os determinantes gerais da opção de um candidato pelo financiamento coletivo para arrecadar recursos de campanha. A regressão logística, entretanto, permite também analisar possíveis efeitos heterogêneos e não lineares desses determinantes.

O primeiro exercício empírico, apresentado no Gráfico 1, busca captar relações não lineares entre os determinantes "orientação partidária" e "anos de escolaridade". O gráfico mostra que, quanto maior a escolaridade do candidato, maior a probabilidade de usar o crowdfunding. Esse efeito parece ser acentuado quando o candidato é de partido de esquerda, centro-esquerda e direita. Como exemplo, um candidato com curso superior (15 anos de escolaridade), de partido de esquerda, tem probabilidade 25 pontos percentuais maior, em média, de usar crowdfunding, se comparado com um de centro, enquanto esse efeito para um candidato de mesma escolaridade, mas de centro-esquerda ou direita, é inferior a 15 pontos percentuais. Para níveis menores de escolaridade, a orientação partidária parece não ter esse impacto. É importante ressaltar, no entanto, que não há diferença significativa, analisada pelos intervalos de confiança de $95 \%$, entre os resultados para partidos de centro-esquerda e direita dentro de cada nível de escolaridade.

\section{GRÁFICO 1 DETERMINANTES DA UTILIZAÇÃO DO CROWDFUNDING: ORIENTAÇÃO PARTIDÁRIA E ANOS DE ESCOLARIDADE}

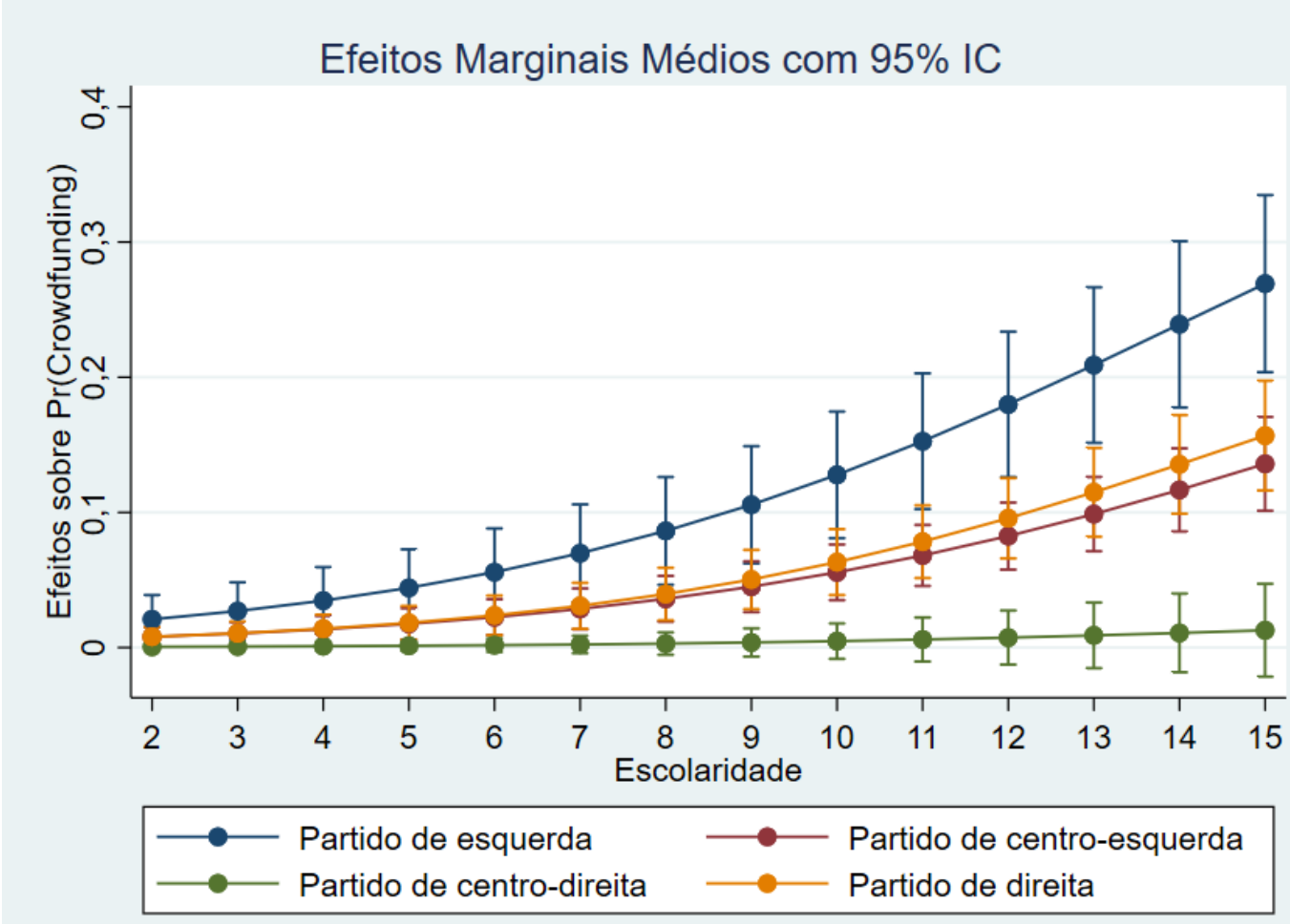

Fonte: Elaborado pelos autores. 
O Gráfico 2 apresenta outro exercício empírico. Nesse caso, consideram-se as probabilidades estimadas por regiões brasileiras. Candidatos da Região Norte são os que têm menor probabilidade de utilizar o crowdfunding (um pouco mais de 5\%), enquanto um da Região Sul tem 17,5\% de probabilidade. Verifica-se que há maior probabilidade estimada sobretudo para candidatos das Regiões Sul e CentroOeste e que tais diferenças são estatisticamente significativas, quando comparadas com os postulantes das demais regiões.

\section{GRÁFICO 2 PROBABILIDADES MÉDIAS ESTIMADAS DE USAR 0 CROWDFUNDING, POR REGIÃO}

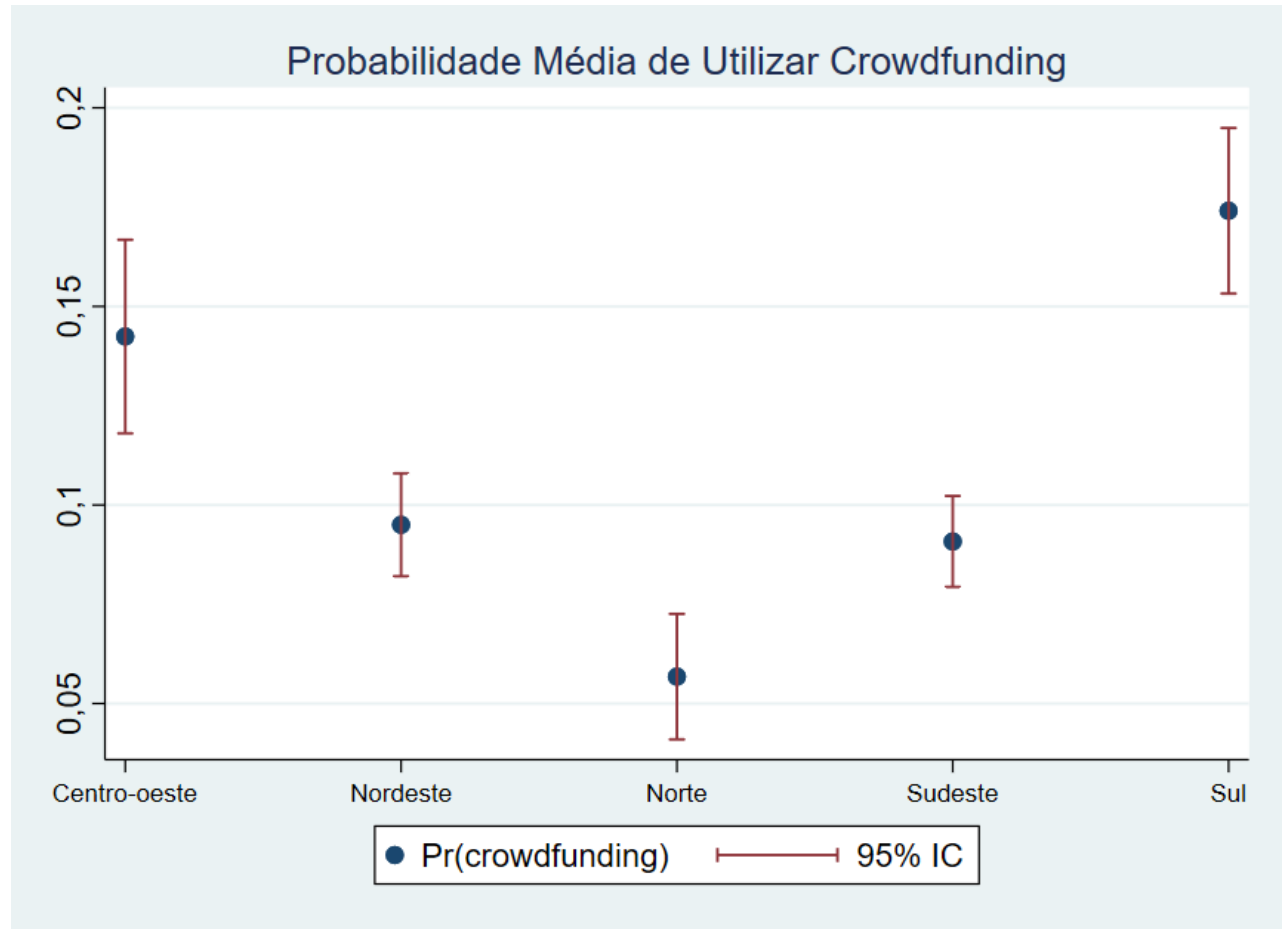

Fonte: Elaborado pelos autores.

Por fim, o último exercício empírico, baseado no modelo apresentado na Tabela 2, busca analisar possíveis heterogeneidades da relação entre probabilidade de utilizar o financiamento coletivo e a idade do candidato. O Gráfico 3 apresenta esses resultados. Verifica-se que a idade do candidato é inversamente relacionada com a chance de usar o crowdfunding. Por exemplo, um candidato de 20 anos tem, em média, cerca de $14 \%$ de chances de utilizar essa estratégia de financiamento de campanha, enquanto um candidato de 80 anos teria cerca de $8 \%$. Essas diferenças são estatisticamente significativas. 


\section{GRÁFICO 3 PROBABILIDADES MÉDIAS ESTIMADAS DE USAR 0 CROWDFUNDING, POR IDADE DO CANDIDATO}

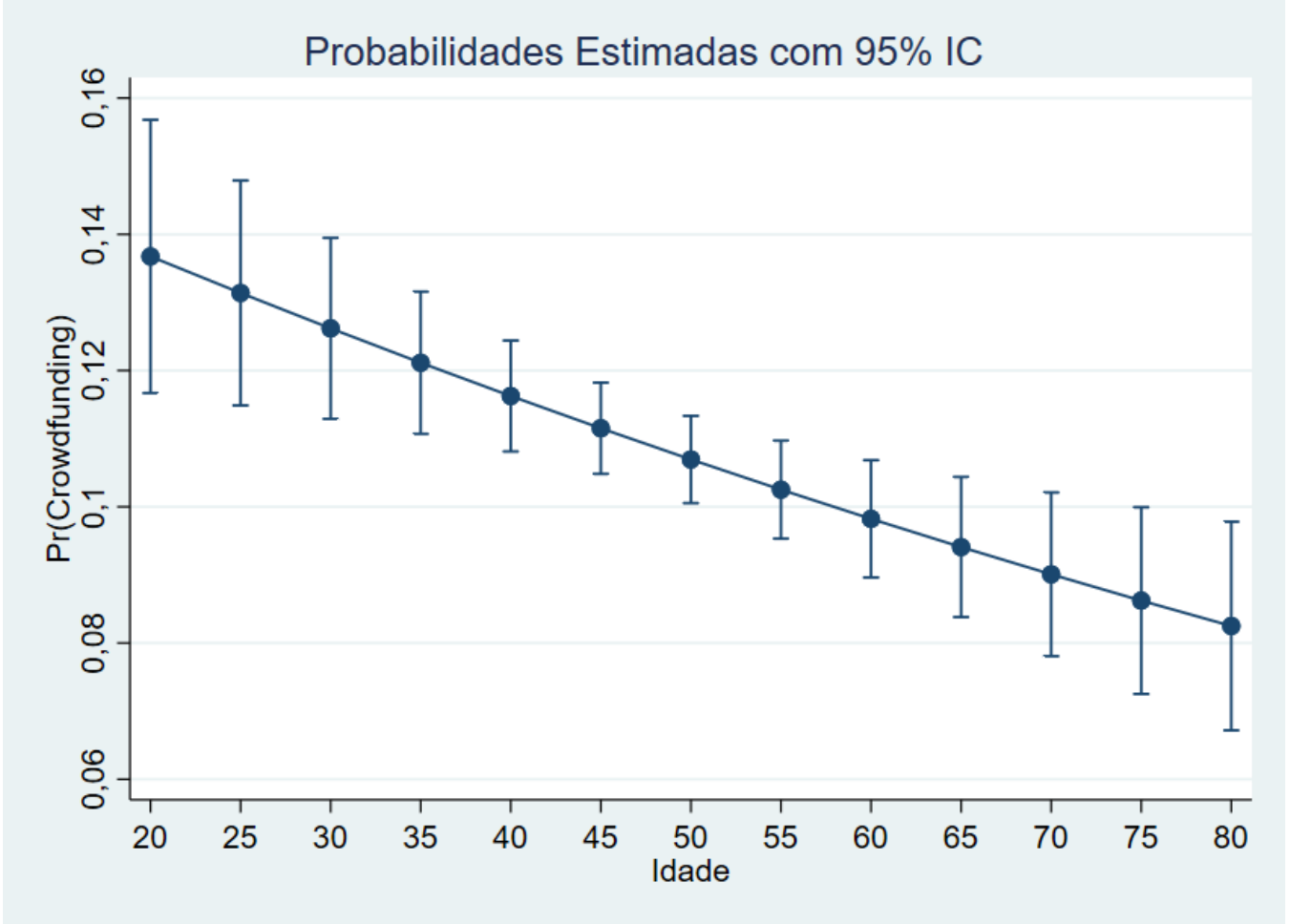

Fonte: Elaborado pelos autores.

Embora o principal objetivo desta subseção seja analisar o perfil do candidato que utilizou a estratégia de financiamento coletivo de campanha, um exercício empírico alternativo é estimar os determinantes do sucesso arrecadatório por essa modalidade. A Tabela 3 apresenta os coeficientes, estimados por mínimos quadrados ordinários (MQO), da estratégia empírica que busca explicar a arrecadação por crowdfunding. São usadas as mesmas variáveis independentes do modelo apresentado na Tabela 2, com exceção da substituição de receita de campanha pela receita líquida, que desconta a receita de crowdfunding. A amostra é restrita apenas aos 813 candidatos que utilizaram o financiamento coletivo.

Segundo as estimativas apresentadas na Tabela 3, candidatos mais jovens, brancos, de partidos de esquerda e com maior receita líquida de campanha têm maior sucesso arrecadatório por crowdfunding. Essas mesmas variáveis já haviam se mostrado significantes preditoras da probabilidade de um candidato optar pelo financiamento coletivo (Tabela 2). Entretanto, candidatos à reeleição e de partidos de orientação de centro-direita, características que não estavam relacionadas com a probabilidade de utilizar o crowdfunding (Tabela 2), parecem ter pior desempenho arrecadatório nessa modalidade de financiamento. 


\section{TABELA 3 RESULTADO DA ESTIMATIVA PARA OS DETERMINANTES DA ARRECADAÇÃO POR CROWDFUNDING}

\begin{tabular}{|c|c|c|c|}
\hline \multicolumn{4}{|c|}{ Coeficientes - MQO } \\
\hline \multicolumn{4}{|c|}{ Variável dependente: arrecadação por crowdfunding (em R\$) } \\
\hline Partido com menos de 5 anos & $\begin{array}{c}941,89 \\
(1682,23)\end{array}$ & Candidato à reeleição & $\begin{array}{l}-5338,21^{*} \\
(3004,82)\end{array}$ \\
\hline Partido de esquerda & $\begin{array}{l}5512,60^{\star *} \\
(2366,28)\end{array}$ & $\begin{array}{l}\text { Receita líquida de campanha (em } \mathrm{R} \$ \\
1.000 .000 .00)\end{array}$ & $\begin{array}{l}8462,04^{\star \star \star} \\
(2308,49)\end{array}$ \\
\hline Partido de centro-esquerda & $\begin{array}{r}1047,38 \\
(1306,89)\end{array}$ & Anos de escolaridade & $\begin{array}{l}269,31 \\
(241,48)\end{array}$ \\
\hline Partido de centro-direita & $\begin{array}{l}2971,71^{\star \star} \\
(1374,66)\end{array}$ & Idade & $\begin{array}{c}-123,95^{\star \star \star} \\
(47,18)\end{array}$ \\
\hline Partido de direita & $\begin{array}{l}2449,64 \\
(1495,10)\end{array}$ & Branco & $\begin{array}{c}2507,83^{\star \star \star} \\
(941,65)\end{array}$ \\
\hline Partidos na coligação & $\begin{array}{c}66,97 \\
(235,14)\end{array}$ & Casado & $\begin{array}{l}-865,42 \\
(1041,34)\end{array}$ \\
\hline Tamanho do partido & $\begin{array}{l}-30,58 \\
(19,61)\end{array}$ & Constante & $\begin{array}{l}-1204,16 \\
(4796,42)\end{array}$ \\
\hline Efeito fixo de UF & & $\operatorname{Sim}$ & \\
\hline $\mathrm{R} 2$ & & 0,1182 & \\
\hline Observações & & 813 & \\
\hline
\end{tabular}

Notas: Coeficientes estimados e erros-padrão robustos entre parênteses. Amostra restrita apenas aos candidatos que utilizaram o crowdfunding.

Significância estatística: ${ }^{\star}$ significa valor- $\mathrm{P}<0,1$; ${ }^{* *}$ valor- $\mathrm{P}<0,05$; ${ }^{* *}$ valor- $\mathrm{P}<0,01$.

Fonte: Elaborada pelos autores.

\subsection{Crowdfunding e desempenho eleitoral}

Pesquisas anteriores sobre os fatores determinantes do desempenho eleitoral no Brasil centraram suas atenções sobretudo em cargos do Poder Executivo (Cavalcante, 2015, 2016; Dias et al., 2018; Dufloth et al., 2019; I. F. A. L. Fernandes \& G. A. A. L. Fernandes, 2017; Sallaberry \& Flach, 2019). Entre os determinantes que influenciam positivamente estão a busca da reeleição, o desempenho fiscal, o investimento público em períodos próximos à eleição, além de atributos pessoais como sexo e profissão do candidato.

Para ampliar a agenda de pesquisa, o presente estudo avança o foco de análise para o Poder Legislativo, em especial o cargo de deputado federal, e incorpora a influência da estratégia de financiamento coletivo. A principal pergunta é: o crowdfunding aumenta as chances de sucesso eleitoral? O modelo proposto 
na equação (2) busca testar essa hipótese já isolando os efeitos das demais características observadas. Os resultados dos efeitos marginais médios de cada característica do candidato sobre a probabilidade de eleição ao cargo de deputado federal em 2018 são apresentados na Tabela 4.

\section{TABELA 4 RESULTADO DA ESTIMATIVA PARA 0 EFEITO DO CROWDFUNDING SOBRE A PROBABILIDADE DE SUCESSO ELEITORAL}

\begin{tabular}{|c|c|c|c|}
\hline \multicolumn{4}{|c|}{ Efeito marginal (EP) - regressão logística } \\
\hline \multicolumn{4}{|c|}{ Variável dependente: $\operatorname{Pr}($ eleito) } \\
\hline Crowdfunding & $\begin{array}{c}0,0555^{\star \star \star} \\
(0,0099)\end{array}$ & Tamanho do partido & $\begin{array}{c}-0,00001 \\
(0,0001)\end{array}$ \\
\hline Partido com menos de 5 anos & $\begin{array}{c}-0,0398^{\star \star \star} \\
(0,0083)\end{array}$ & Candidato à reeleicao & $\begin{array}{l}0,0551^{\star \star \star} \\
(0,0138)\end{array}$ \\
\hline Partido de esquerda & $\begin{array}{l}0,0050 \\
(0,0144)\end{array}$ & $\begin{array}{l}\text { Receita de campanha (em } \mathrm{R} \$ \\
1.000 .000,00)\end{array}$ & $\begin{array}{c}0,0829^{\star \star \star} \\
(0,0052)\end{array}$ \\
\hline Partido de centro-esquerda & $\begin{array}{c}0,0388^{\star \star \star} \\
(0,0099)\end{array}$ & Anos de escolaridade & $\begin{array}{l}0,0029^{\star \star} \\
(0,0013)\end{array}$ \\
\hline Partido de centro-direita & $\begin{array}{l}0,0217^{\star *} \\
(0,0091)\end{array}$ & Idade & $\begin{array}{c}-0,0014^{\star \star *} \\
(0,0002)\end{array}$ \\
\hline Partido de direita & $\begin{array}{c}0,0723^{\star \star \star} \\
(0,0165)\end{array}$ & Branco & $\begin{array}{c}0,0074 \\
(0,0054)\end{array}$ \\
\hline Partidos na coligação & $\begin{array}{c}0,0033^{\star \star \star} \\
(0,0012)\end{array}$ & Casado & $\begin{array}{c}0,0162^{\star \star \star} \\
(0,0049)\end{array}$ \\
\hline Efeito fixo de UF & & Sim & \\
\hline Pseudo-R2 & & 0,4301 & \\
\hline Observações & & 7.484 & \\
\hline
\end{tabular}

Notas: Efeitos marginais estimados e erros-padrão robustos entre parênteses.

Significância estatística: ${ }^{\star}$ significa valor- $\mathrm{P}<0,1 ;{ }^{* \star}$ valor- $\mathrm{P}<0,05 ;{ }^{* *}$ valor- $\mathrm{P}<0,01$

Fonte: Elaborada pelos autores.

A variável de interesse é a dummy de utilização do crowdfunding. O resultado indica que a probabilidade de sucesso eleitoral é, em média, 5,55 pontos percentuais maior para os candidatos que usam tal modalidade de financiamento de campanha. Essa estimativa controla o impacto das demais variáveis explicativas. Ou seja, para um mesmo montante de receita de campanha, mesmo partido e ideologia, mesma idade etc., a estratégia de utilização de crowdfunding é associada positivamente ao sucesso eleitoral. 
Essa relação pode ser mais facilmente entendida no Gráfico 4, que apresenta o efeito da utilização do financiamento coletivo sobre a probabilidade de eleição, considerando diferentes níveis de receitas de campanha. A utilização do crowdfunding, como já indicado, amplia as chances eleitorais. Esse resultado pode ser, entretanto, potencializado pelo montante total arrecadado. Por exemplo, um candidato que arrecadou $\mathrm{R} \$ 1,7$ milhão e utilizou o crowdfunding tem aproximadamente 25 pontos percentuais a mais de chances de sucesso eleitoral. Surgem hipóteses de que a contribuição financeira individual para campanhas eleitorais pode ter um efeito engajador, fazendo o doador se sentir parte, coprodutor da campanha e corresponsável pelo sucesso eleitoral. Ou, ainda, que o crowdfunding tem força argumentativa de marketing eleitoral na percepção do eleitorado, aliado ao argumento de rejeição de fundo eleitoral, recursos do partido ou autofinanciamento do candidato, podendo gerar uma propensão maior do eleitor, mesmo que não doador, a votar em tal candidato(a).

O efeito positivo do financiamento coletivo, no entanto, não tem relação linear para diferentes montantes de arrecadação total de campanha. Segundo as estimativas, o impacto do crowdfunding sobre a probabilidade de eleição atinge um ponto máximo para receitas de campanha de cerca de $\mathrm{R} \$ 1,7$ milhão. Esse resultado não significa que exista um ponto ótimo de arrecadação de campanha; apenas que o efeito do crowdfunding sobre o sucesso eleitoral diminui para campanhas com muitos recursos.

\section{GRÁFICO 4 EFEITOS DA UTILIZAÇÃO DO CROWDFUNDING SOBRE A PROBABILIDADE DE SUCESSO ELEITORAL, POR NÍVEL DE RECEITA ELEITORAL}

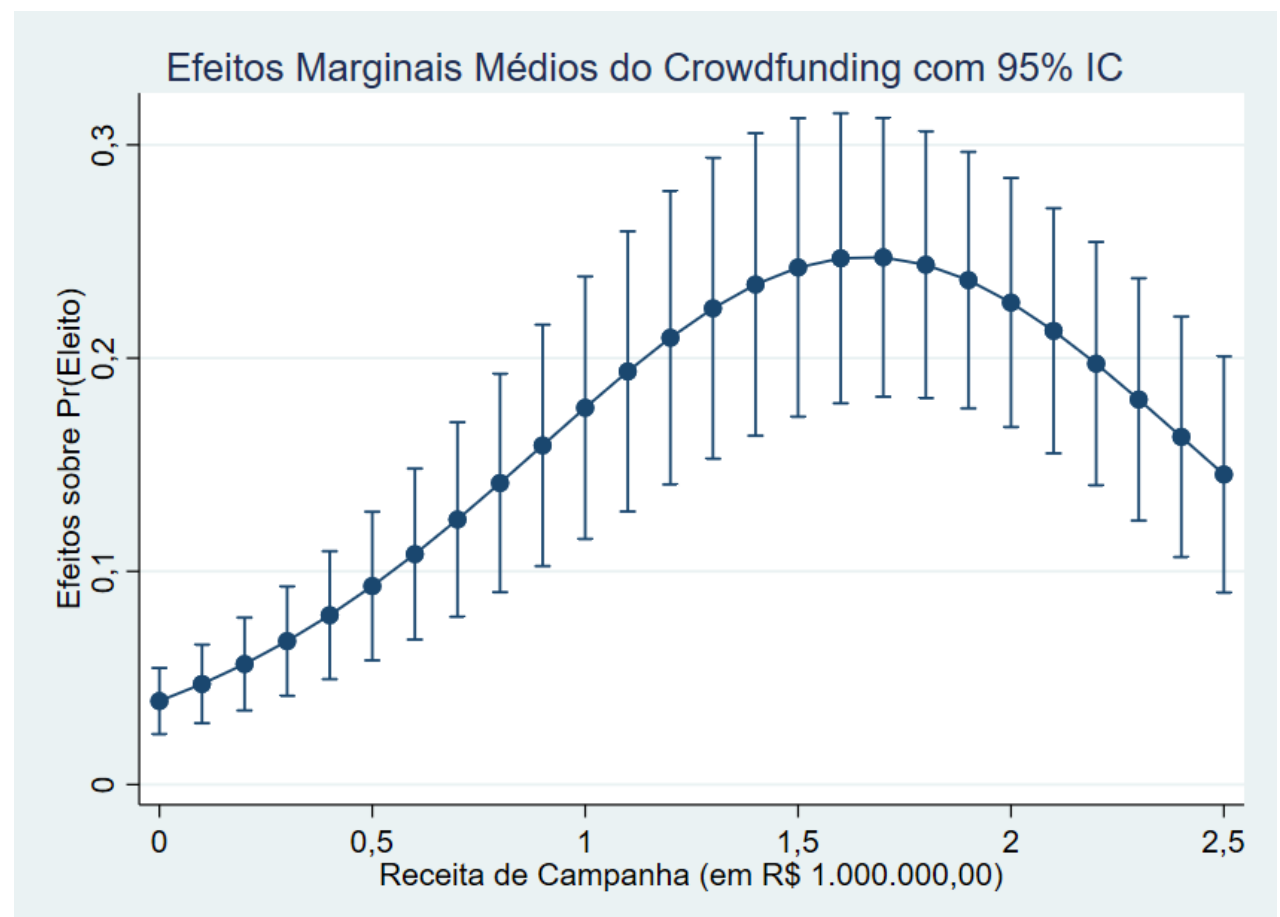

Fonte: Elaborado pelos autores. 
Com relação às demais variáveis do modelo, buscar a reeleição é um dos fatores que mais ampliam as chances de sucesso eleitoral (5,5 pontos percentuais). Esse resultado já fora evidenciado por Sallaberry e Flach (2019). De maneira geral, candidatos mais escolarizados, mais jovens, casados, de partidos mais antigos, de centro ou de esquerda, que tenham mais partidos na coligação e mais recursos de campanha são os que têm maior probabilidade de ser eleitos ao cargo de deputado federal. A raça do postulante e o tamanho da bancada na Câmara Federal não têm, segundo as estimativas, relação significativa com as chances de sucesso eleitoral.

Outra possibilidade de análise, que pode oferecer robustez às evidências encontradas, é relacionada com o efeito do montante arrecadado por crowdfunding sobre o sucesso eleitoral. Com esse objetivo, estima-se a mesma especificação cujos resultados são expostos na Tabela 4, alterando somente a variável qualitativa de crowdfunding por uma variável de montante arrecadado com essa modalidade e a variável de receita total de campanha, descontado o financiamento coletivo (receita líquida de campanha). $\mathrm{O}$ resultado dessa especificação é apresentado na Tabela 5, tanto para a amostra restrita aos candidatos que utilizaram o crowdfunding quanto para a amostra completa.

Os resultados presentes na Tabela 5 indicam que o montante arrecadado por crowdfunding também é um preditor do sucesso eleitoral. O efeito marginal estimado para essa variável indica que, em média, a arrecadação de $\mathrm{R} \$ 1.000,00$ a mais de financiamento coletivo está associado a um aumento de 0,3 ponto percentual na probabilidade de sucesso eleitoral, quando analisada a amostra restrita aos usuários do crowdfunding. Para a amostra completa, essa estimativa é semelhante: 0,2 ponto percentual. As demais variáveis dos modelos apresentados na Tabela 5 estão em linha com as evidências já obtidas na especificação da Tabela 4.

\section{TABELA 5 RESULTADO DA ESTIMAÇÃO PARA 0 EFEITO DO CROWDFUNDING SOBRE A PROBABILIDADE DE SUCESSO ELEITORAL}

\begin{tabular}{|c|c|c|c|c|c|c|c|}
\hline \multicolumn{8}{|c|}{ Efeito marginal (EP) - regressão logística } \\
\hline \multicolumn{8}{|c|}{ Variável dependente: $\operatorname{Pr}$ (eleito) } \\
\hline \multicolumn{4}{|c|}{ (1) } & \multicolumn{4}{|c|}{ (2) } \\
\hline $\begin{array}{l}\text { Arrecadação por } \\
\text { crowdfunding } \\
\text { (em } \mathrm{R} \$ \text { ) }\end{array}$ & $\begin{array}{c}0,000003^{\star \star \star} \\
(0.000001)\end{array}$ & $\begin{array}{l}\text { Tamanho do } \\
\text { partido }\end{array}$ & $\begin{array}{c}0,0004 \\
(0,0005)\end{array}$ & $\begin{array}{c}\text { Arrecadação } \\
\text { por } \\
\text { Crowdfunding } \\
\text { (em R\$) }\end{array}$ & $\begin{array}{l}0,000002^{\star \star \star} \\
(0,0000004)\end{array}$ & $\begin{array}{c}\text { Tamanho do } \\
\text { partido }\end{array}$ & $\begin{array}{c}0,0001 \\
(0,0001)\end{array}$ \\
\hline $\begin{array}{l}\text { Partido com } \\
\text { menos de } 5 \\
\text { anos }\end{array}$ & $\begin{array}{c}-0,1553^{\star \star \star} \\
(0,0346)\end{array}$ & $\begin{array}{l}\text { Candidato à } \\
\text { reeleicao }\end{array}$ & $\begin{array}{c}0,2019^{\star * *} \\
(0,0686)\end{array}$ & $\begin{array}{l}\text { Partido com } \\
\text { menos de } 5 \\
\text { anos }\end{array}$ & $\begin{array}{c}-0,0362^{\star \star \star} \\
(0,0095)\end{array}$ & $\begin{array}{l}\text { Candidato à } \\
\text { reeleicao }\end{array}$ & $\begin{array}{l}0,0599^{* * *} \\
(0,0142)\end{array}$ \\
\hline $\begin{array}{l}\text { Partido de } \\
\text { esquerda }\end{array}$ & $\begin{array}{l}0,1605^{\star} \\
(0,0881)\end{array}$ & $\begin{array}{c}\text { Receita líquida } \\
\text { de campanha } \\
\text { (em } \mathrm{R} \$ \\
1.000 .000,00)\end{array}$ & $\begin{array}{l}0,1550^{\star \star \star} \\
(0,0336)\end{array}$ & $\begin{array}{l}\text { Partido de } \\
\text { esquerda }\end{array}$ & $\begin{array}{l}-0,0001 \\
(0,0147)\end{array}$ & $\begin{array}{c}\text { Receita líquida } \\
\text { de campanha } \\
\text { (em } \mathrm{R} \$ \\
1.000 .000,00)\end{array}$ & $\begin{array}{l}0,0795^{\star \star \star} \\
(0,0050)\end{array}$ \\
\hline
\end{tabular}




\begin{tabular}{|c|c|c|c|c|c|c|c|}
\hline \multicolumn{8}{|c|}{ Efeito marginal (EP) - regressão logística } \\
\hline \multicolumn{8}{|c|}{ Variável dependente: $\operatorname{Pr}($ eleito) } \\
\hline \multicolumn{4}{|c|}{ (1) } & \multicolumn{4}{|c|}{ (2) } \\
\hline $\begin{array}{l}\text { Partido de } \\
\text { centro-esquerda }\end{array}$ & $\begin{array}{c}0,2159^{\star \star \star} \\
(0,0670)\end{array}$ & $\begin{array}{c}\text { Anos de } \\
\text { escolaridade }\end{array}$ & $\begin{array}{l}0,0006 \\
(0,0053)\end{array}$ & $\begin{array}{l}\text { Partido de } \\
\text { centro- } \\
\text { esquerda }\end{array}$ & $\begin{array}{c}0,0422^{\star \star \star} \\
(0,0099)\end{array}$ & $\begin{array}{c}\text { Anos de } \\
\text { escolaridade }\end{array}$ & $\begin{array}{l}0,0034^{\star \star} \\
(0,0013)\end{array}$ \\
\hline $\begin{array}{l}\text { Partido de } \\
\text { centro-direita }\end{array}$ & $\begin{array}{l}0,1998^{\star \star} \\
(0,0812)\end{array}$ & Idade & $\begin{array}{c}-0,0021^{\star \star} \\
(0,0011)\end{array}$ & $\begin{array}{c}\text { Partido de } \\
\text { centro-direita }\end{array}$ & $\begin{array}{l}0,0218^{* *} \\
(0,0090)\end{array}$ & Idade & $\begin{array}{c}-0,0013^{\star \star *} \\
(0,0002)\end{array}$ \\
\hline Partido de direita & $\begin{array}{c}0,3413^{\star * \star} \\
(0,0768)\end{array}$ & Branco & $\begin{array}{c}0,0265 \\
(0,0252)\end{array}$ & $\begin{array}{l}\text { Partido de } \\
\text { direita }\end{array}$ & $\begin{array}{l}0,0717^{\star \star \star} \\
(0,0167)\end{array}$ & Branco & $\begin{array}{c}0,0073 \\
(0,0054)\end{array}$ \\
\hline $\begin{array}{l}\text { Partidos na } \\
\text { coligação }\end{array}$ & $\begin{array}{c}0,0002 \\
(0,0062)\end{array}$ & Casado & $\begin{array}{l}-0,0300 \\
(0,0223)\end{array}$ & $\begin{array}{c}\text { Partidos na } \\
\text { coligação }\end{array}$ & $\begin{array}{c}0,0033^{\star \star \star} \\
(0,0012)\end{array}$ & Casado & $\begin{array}{c}0,0174^{\star * \star} \\
(0,0048)\end{array}$ \\
\hline Amostra & $\begin{array}{l}\text { Apenas candid } \\
\text { crowdfunding }\end{array}$ & s que usaram & & Todos os candic & tos & & \\
\hline Efeito fixo de UF & Sim & & & Sim & & & \\
\hline Pseudo-R2 & 0,3832 & & & 0,4296 & & & \\
\hline Observações & 791 & & & 7.484 & & & \\
\hline
\end{tabular}

Notas: Efeitos marginais estimados e erros-padrão robustos entre parênteses.

Significância estatística: ${ }^{\star}$ significa valor-P $<0,1 ;{ }^{\star *}$ valor- $\mathrm{P}<0,05 ;{ }^{\star \star \star}$ valor- $\mathrm{P}<0,01$.

Fonte: Elaborada pelos autores.

\section{CONCLUSÕES}

Este trabalho teve como objetivo analisar a relação entre a estratégia de arrecadação de recursos para campanha por meio do crowdfunding e as chances de sucesso nas eleições para deputado federal em 2018. Além disso, investigaram-se possíveis características socioeconômicas e demográficas associadas à decisão de adoção do financiamento coletivo como alternativa arrecadatória na campanha eleitoral.

Como visto na literatura internacional (Bonneau, 2007; Hindman, 2005; Sebold et al., 2012) e nas pesquisas já realizadas sobre as eleições no Brasil (Cervi, 2013; Mancuso \& Speck, 2015; Sacchet \& Speck, 2012), existem evidências sobre a influência da quantidade de recursos para campanha e as chances de vitória eleitoral. Neste trabalho, buscou-se complementar o conhecimento acumulado até agora na ciência política, focalizando a influência dessa novidade de financiamento eleitoral no cenário brasileiro, de maneira a aferir se a utilização do crowdfunding influencia o desempenho eleitoral dos candidatos a deputado federal.

Para tanto, foi usada uma metodologia de regressão logística que considerou duas variáveis dependentes diferentes. A primeira estratégia buscou investigar os determinantes socioeconômicos e demográficos da opção de um candidato pelo crowdfunding. A segunda analisou o efeito da utilização do financiamento coletivo sobre as chances de sucesso eleitoral. Os resultados sugerem que o crowdfunding foi estatisticamente mais usado por candidatos brancos, jovens, de alta escolaridade e da Região Sul. Há evidências também de que o crowdfunding seja uma estratégia eleitoral utilizada especialmente por 
candidatos de partidos de criação recente, de esquerda, centro-esquerda ou direita - os de centro e centro-direita tiveram menor utilização -, e de partidos com maior bancada e mais legendas na coligação.

Com relação às chances eleitorais, a estratégia empírica utilizada aponta que, em média, a probabilidade de sucesso eleitoral é 5,55 pontos percentuais maior para os candidatos que optaram por essa modalidade de financiamento de campanha. Essa estimativa é obtida já considerando vários outros determinantes como variáveis de controle. Ou seja, para um mesmo montante de recursos de campanha, por exemplo, se parte dessa arrecadação for oriunda do financiamento coletivo, a probabilidade de eleição é, em média, maior. Exercícios empíricos alternativos, que tratam o crowdfunding como variável quantitativa (arrecadação por essa modalidade), foram realizados e evidenciam a robustez dos resultados do presente estudo.

Um aumento das chances de vitória eleitoral de 5,5 pontos percentuais não é desprezível, colocando o crowdfunding como uma estratégia que ultrapassa os efeitos arrecadatórios - para tocar aspectos comportamentais, como os potenciais ganhos simbólicos (campanha menos tradicional) -, os efeitos motivacionais e de pertencimento do doador (campanha coletiva) e os efeitos de confiança e percepção da qualidade do candidato e suas propostas (Kusuramani \& Zo, 2019).

Como limitações do estudo, a variável "ideologia do partido político" pode ter diversas formas de tratamento à medida que se adota uma das várias classificações disponíveis nos estudos da ciência política. Ademais, os próprios partidos variam de ideologia com o passar dos anos e novos ciclos eleitorais acontecem (Zucco \& Power, 2021). Acredita-se, no entanto, que os possíveis efeitos dessa variável não sejam suficientes para invalidar as relações causais identificadas entre a utilização do crowdfunding e as chances de sucesso eleitoral.

Ainda como limitação aos resultados do estudo, destaca-se que não foi usada uma estratégia de identificação causal das relações estimadas. Assim, as estimativas apresentadas não podem ser interpretadas como impactos causais, e sim como associações. Pode haver variáveis não observadas ou omitidas que sejam relacionadas tanto com a forma utilizada de financiamento de campanha quanto com as chances de sucesso eleitoral. Caso isso aconteça, os efeitos marginais estimados serão viesados.

Futuras pesquisas poderiam, portanto, propor um método de avaliação de causalidade para estabelecer efeitos estimados mais precisos. Uma das possibilidades é verificar a influência do crowdfunding sobre a quantidade de votos ou a proporção de votos recebidos, de modo a isolar efeitos das regras brasileiras para eleições proporcionais em lista aberta, que muitas vezes acabam elegendo candidatos que não necessariamente receberam o maior número de votos. Além disso, pesquisas qualitativas são sugeridas para auxiliar na interpretação dos resultados verificados empiricamente.

De igual modo, sugere-se a verificação desses efeitos sobre as eleições municipais, em especial para o cargo de vereador. Com a disponibilização de dados e da prestação de contas definitivas das campanhas eleitorais de 2020, pode-se chegar a uma conclusão mais robusta sobre os efeitos do crowdfunding sobre o desempenho eleitoral nas eleições gerais e locais.

Por fim, a Emenda Constitucional 97/2017, que instituiu o fim das coligações partidárias nas eleições proporcionais, que já foi implementada nas eleições municipais de 2020, terá sua primeira aplicação em eleições gerais de 2022. São conhecidos os efeitos desse tipo de configuração sobre o sistema eleitoral e partidário (Carreirão \& Nascimento, 2010; P. Silva, Davidian, Freitas \& Cazzolato, 2015). Ainda desconhecida, porém, é a combinação dessa nova regra eleitoral com a dinâmica de arrecadação de fundos e se os efeitos do crowdfunding sobre as chances de sucesso eleitoral serão mantidos. 
As recentes mudanças nos padrões de financiamentos das campanhas eleitorais no Brasil têm levado candidatos e partidos políticos a debater alternativas substitutivas ao modelo de financiamento empresarial que predominou até 2015. Este artigo contribuiu para o entendimento de que a adoção do crowdfunding pode trazer benefícios positivos para o aumento das chances de sucesso eleitoral dos candidatos. Também trouxe resultados que podem ter validade prática para que candidatos e partidos adequem suas estratégias de financiamentos nas eleições vindouras.

Apesar de ainda pouco usado no Brasil, o crowdfunding eleitoral merece atenção como alternativa de financiamento coletivo pelas contribuições espontâneas individuais, dando seus primeiros passos em direção à sua institucionalização como modalidade de arrecadação de fundos para campanhas eleitorais no país. 


\section{REFERÊNCIAS}

Amedomar, A. A. (2015). O crowdfunding de recompensas como alternativa de capital empreendedor para Empresas de Base Tecnológicas no Brasil: um estudo descritivo-exploratório (Dissertação de Mestrado). Universidade de São Paulo, São Paulo, SP.

Bando. (2020). Consultorias para crowdfunding. Recuperado de www.somosbando.com

Bonneau, C. W. (2007). Campaign fundraising in state Supreme Court elections. Social Sciences Quarterly, 88, 68-85.

Carreirão, Y. S., Nascimento, F. P. (2010). As coligações nas eleições para os cargos de governador, senador, deputado federal e deputado estadual no Brasil (1986-2006). Revista Brasileira de Ciência Política, 4, 75-104.

Cavalcante, P. (2015). Vale a pena ser um bom prefeito? Comportamento eleitoral e reeleição no Brasil. Opinião Pública, 21(1), 87-104.

Cavalcante, P. (2016). Desempenho fiscal e eleições no Brasil: uma análise comparada dos governos municipais. Revista de Administração Pública, 50(2), 307-330

Cervi, E. U. (2013). Doações de campanha e desempenho eleitoral: uma análise comparativa sobre as eleições para prefeito de capitais brasileiras em 2008 e 2012. Agenda Política, 1(1), 26-54.

Dias, B. P., Nossa, V., \& Monte-Mor, D. S. (2018). O investimento público influencia na reeleição? Um estudo empírico nos municípios do estado do Espírito Santo. Revista de Administração Pública, 52(5), 880-898.

Dufloth, S. C., Horta, C. J. G., Silva, M. M., Costa, M. L. M., \& Rocha, M. S. (2019). Atributos e chances de sucesso eleitoral de prefeitos no Brasil. Revista de Administração Pública, 53(1), 214-234.

Fernandes, I. F. A. L., \& Fernandes, G. A. A. L. (2017). A importância do crescimento econômico local na escolha do chefe do Executivo no Brasil. Revista de Administração Pública, 51(4), 653-688.

Hindman, M. (2005). The real lessons of Howard Dean: reflections on the first digital campaign. Perspectives on Politics, 3(1), 121-128.

Idea. (2018). Online political crowdfunding: political party innovation prime 2 . Recuperado de www.idea. int/sites/default/files/publications/online-politicalcrowdfunding.pdf

Kusuramani, R., \& Zo, H. (2019). Why people participate in online political crowdfunding: a civic voluntarism perspective. Telematics and informatics, $41,168-181$.

Mancuso, W. P., Camargo, N. F, \& Horochovski, R. R. (2016). Empresários e financiamento de campanhas na eleição presidencial brasileira de 2014. Teoria \& Pesquisa - Revista de Ciência Política, 25(3), 38-64.

Mancuso, W. P., \& Speck, B. W. (2015). Financiamento empresarial na eleição para deputado federal (20022010): determinantes e consequências. Teoria \& Sociedade, 23(2), 103-125.

McMenamin, I. (2012). If money talks, what does it say? Varieties of capitalism and business financing of parties. World Politics, 64(1), 1-38.

Mohallem, M. F., \& Costa, G. S. (2015). Crowdfunding e o futuro do financiamento eleitoral no Brasil. Estudos Eleitorais, 10(2), 153-175.

Monteiro, M. C. P. (2014). Crowdfunding no Brasil: uma análise sobre as motivações de quem participa (Dissertação de Mestrado). Fundação Getulio Vargas, Rio de Janeiro, RJ.

Rubio, D. F. (2005). Financiamento de partidos e campanhas: fundos públicos versus fundos privados. Novos Estudos Cebrap, 73, 6-16.

Sacchet, T., \& Speck, B. (2012). Dinheiro e sexo na política brasileira: financiamento de campanha e desempenho eleitoral em cargos legislativos. In J. E. E. Alves, C. R. J. Pinto, \& F. Jordão (Orgs.), Mulheres nas eleições de 2010. São Paulo, SP: ABCP.

Sallaberry, J., \& Flach, L. (2019). Contemporary economic determinants for the choice of the leaders of the Brazilian public administration. Revista Eletrônica de Administração, 25(2), 119-149.

Santano, A. C. (2016). O financiamento coletivo de campanhas eleitorais como medida econômica de democratização de eleições. Estudos Eleitorais, 11(2), 31-66.

Santos, R. D. (2009). A economia política das Eleições 2002: um estudo sobre a concentração de financiamento de campanha para deputado federal (Dissertação de Mestrado). Universidade Federal Fluminense, Niterói, RJ. 
Scheeffer, F. (2018). Esquerda e direita hoje: uma análise das votações na Câmara dos Deputados. Curitiba, PR: Appris.

Sebold, K., Limbocker, S., Dowdle, A., \& Stewart, P. (2012). The political geography of campaign finance: contributions to 2008 republican presidential candidates. Political Sciences and Politics, 45(4), 688-693.

Silva, P., Davidian, A., Freitas, A., \& Cazzolato, J. D. (2015). Reforma política no Brasil: indagações sobre o impacto no sistema partidário e na representação. Opinião Pública, 21(1), 1-32.

Sokolov, A. V. (2015). Russian political crowdfunding Demokratizatsiya: the journal of post-soviet. Democratization, 23, 117-149.
Speck, B. W. (2007). O financiamento de campanhas eleitorais. In L. Avritzer (Org.), Reforma política no Brasil. Belo Horizonte, MG: Editora UFMG.

Tarouco, G. S., \& Madeira, R. M. (2015). Os partidos brasileiros segundo seus estudiosos: análise de um expert survey. Civitas - Revista de Ciências Sociais, 15(1), 24-39.

Zovatto, D. (2005). Financiamento dos partidos e campanhas eleitorais na América Latina: uma análise comparada. Opinião Pública, 11(2), 287-336.

Zucco, C., Jr., \& Power, T. (2021). Fragmentation without cleavages? Endogenous fractionalization in Brazilian party system. Comparative Politics, 53(3), 477-500.

\section{Leonardo Secchi}

https://orcid.org/0000-0002-9073-0343

Ph.D. em Estudos Políticos pela Universidade de Milão; Professor do Departamento de Administração Pública e do Programa de Pós-Graduação em Administração da Universidade do Estado de Santa Catarina (UDESC); Presidente da Sociedade Brasileira de Administração Pública (SBAP). E-mail: leonardo.secchi@udesc.br

\section{Marcos Vinicio Wink Junior}

https://orcid.org/0000-0003-2206-5211

Doutor em Economia pela Universidade Federal do Rio Grande do Sul (UFRGS); Professor do Departamento de Ciências Econômicas e do Programa de Pós-Graduação em Administração da Universidade do Estado de Santa Catarina (UDESC).E-mail: marcos.winkjunior@udesc.br

\section{Cryslan Jorjan de Moraes}

\section{https://orcid.org/0000-0001-5408-5925}

Graduado em Administração Pública pela Universidade do Estado de Santa Catarina (UDESC); Vereador no município de São José, Santa Catarina. E-mail: cryslan@live.com 


\section{APÊNDICE}

\section{QUADRO A CRITÉRIOS PARA CATEGORIZAÇÃO IDEOLÓGICA DOS PARTIDOS POLÍTICOS}

\begin{tabular}{|c|c|c|c|}
\hline Sigla em 2010 & Sigla em 2020 & $\begin{array}{c}\text { Classificação } \\
\text { Tarouco e Madeira (2015) }\end{array}$ & Categorização \\
\hline PCO & PCO & 1,1 & Esquerda \\
\hline PSTU & PSTU & 1,2 & Esquerda \\
\hline Psol & Psol & 1,4 & Esquerda \\
\hline \multirow[t]{2}{*}{ РСВ } & РСВ & 1,5 & Esquerda \\
\hline & UP & Categorização autônoma & Esquerda \\
\hline PCdoB & PCdoB & 2,3 & Centro-esquerda \\
\hline PT & PT & 2,9 & Centro-esquerda \\
\hline PSB & PSB & 3 & Centro-esquerda \\
\hline PDT & PDT & 3,3 & Centro-esquerda \\
\hline \multirow[t]{3}{*}{ PV } & PV & 3,5 & Centro-esquerda \\
\hline & Pros & Categorização autônoma & Centro-esquerda \\
\hline & Rede & Categorização autônoma & Centro \\
\hline PPS & Cidadania & 4 & Centro \\
\hline PMDB & MDB & 4,2 & Centro \\
\hline PMN & PMN & 4,4 & Centro \\
\hline PSDB & PSDB & 4,6 & Centro \\
\hline PT do B & Avante & 4,7 & Centro \\
\hline \multirow[t]{3}{*}{ РTB } & РTB & 5 & Centro \\
\hline & SD & Categorização autônoma & Centro \\
\hline & PMB & Categorização autônoma & Centro \\
\hline PTC & PTC & 5,1 & Centro-direita \\
\hline PTN & Podemos & 5,1 & Centro-direita \\
\hline PRB & Republicanos & 5,1 & Centro-direita \\
\hline PSC & PSC & 5,2 & Centro-direita \\
\hline PRTB & PRTB & 5,3 & Centro-direita \\
\hline PSDC & $\mathrm{DC}$ & 5,4 & Centro-direita \\
\hline
\end{tabular}


RAP |Crowdfunding e desempenho eleitoral no Brasil: análise estatística das eleições para deputado federal em 2018

\begin{tabular}{cccc}
\hline Sigla em $\mathbf{2 0 1 0}$ & Sigla em 2020 & $\begin{array}{c}\text { Classificação } \\
\text { Tarouco e Madeira (2015) }\end{array}$ & Categorização \\
\hline PR & PL & 5,4 & Centro-direita \\
& Patriota & Categorização autônoma & Centro-direita \\
\hline PS & PP & Categorização autônoma & Direita \\
\hline PSL & PSL & 6 & Direita \\
\hline DEM & DEM & Categorização autônoma & Direita \\
\hline
\end{tabular}

Fonte: Elaborado pelos autores.

\section{QUADRO B SIGLAS QUE FORAM INCORPORADAS (PREVALECEU A CLASSIFICAÇÃO DO PARTIDO INCORPORADOR)}

\begin{tabular}{l|c} 
PHS & Incorporado ao Podemos \\
PRP & Incorporado ao Patriota \\
PPL & Incorporado ao PCdoB \\
\hline
\end{tabular}

Fonte: Elaborado pelos autores. 